\title{
Ultrasonographic Diagnosis of Non-displaced Avulsion Fracture of the Acromion: A Case Report
}

\author{
Chang Han Lee, $\mathrm{MD}^{1}$, Young-Ah Choi, $\mathrm{MD}^{2}$, Shi-Uk Lee, $\mathrm{MD}, \mathrm{PhD}^{3}$
}

\begin{abstract}
${ }^{1}$ Department of Rehabilitation Medicine, Maryknoll Medical Center, Busan; ${ }^{2}$ Department of Rehabilitation Medicine, Seoul National University College of Medicine, Seoul; ${ }^{3}$ Department of Rehabilitation Medicine, Seoul National University Boramae Medical Center, Seoul, Korea
\end{abstract}

\begin{abstract}
Avulsion fracture of the acromion is rare. It is difficult to diagnosis because there is little displacement and it occurs even without direct trauma. We experienced a case without direct trauma that was diagnosed with ultrasonography. A 55-year-old male patient visited our outpatient clinic with shoulder pain resulting from a significant stress at the trapezius muscle during lifting of a steel reinforcement. Simple radiography revealed a calcific deposit over the acromion rather than a fracture. Avulsion fracture was identified with ultrasonography. This is the first report demonstrating that ultrasonography has an advantage over radiographs in the diagnosis of an avulsion fracture of the acromion of the scapula.
\end{abstract}

Keywords Acromion, Bone fractures, Ultrasonography

\section{INTRODUCTION}

Fractures of the scapula are relatively rare, representing $3 \%-5 \%$ of all shoulder injuries and $0.4 \%-1 \%$ of all fractures $[1,2]$. Acromial fractures account for only $8 \%$ of all scapular fractures [3]. Avulsion fractures of the acromion occur as a result of an acute injury without direct trauma.

Received April 3, 2014; Accepted August 22, 2014

Corresponding author: Shi-Uk Lee

Department of Rehabilitation Medicine, Seoul National University Boramae Medical Center, 20 Boramae-ro 5-gil, Dongjak-gu, Seoul 156707 , Korea

Tel: +82-2-870-2671, Fax: +82-2-870-3866, E-mail: ShiUk.Lee@gmail.com

(c) This is an open-access article distributed under the terms of the Creative Commons Attribution Non-Commercial License (http://creativecommons. org/licenses/by-nc/4.0) which permits unrestricted noncommercial use, distribution, and reproduction in any medium, provided the original work is properly cited.

Copyright (C) 2015 by Korean Academy of Rehabilitation Medicine
Patients with this type of fracture usually recover quickly with non-operative treatment [4]. For the diagnosis of fracture simple radiography is usually sufficient. However, for avulsion fracture of acromion, it is difficult to diagnose through simple radiographs because there are few cases with displacement. In cases with non-displaced fracture, ultrasonography might be helpful. Investigators have reported the advantage of ultrasonography in the diagnosis of the non-displaced fractures of the greater tuberosity of the humerus and clinically suspected scaphoid fracture $[5,6]$.

To our knowledge, no case report has described the usefulness of ultrasonography in the diagnosis of avulsion fracture of acromion. Herein we report a case of avulsion fracture of acromion diagnosed with ultrasonography, in which simple radiography revealed small calcific deposit over acromioclavicular joint. 


\section{CASE REPORT}

A 55-year-old man visited our outpatient clinic with shoulder pain and restricted movement. He had severe shoulder pain which occurred suddenly during the lifting of a steel reinforcement 4 days previously. He had no remarkable trauma or surgical history. It was a first time that he had shoulder pain. In physical examination, a range of motion of the right shoulder was decreased slightly with pain. He had tender points at the right acromioclavicular joint and acromion. There was a positive response in the acromioclavicular joint compression test. We requested radiographs of the shoulder for initial evaluation. There was no definite abnormality in the anterior-posterior view obtained with the both clavicles of the patient bearing weight (Fig. 1). The radiograph of shoulder in anterior-posterior view showed only small calcific deposit at right acromioclavicular joint (Fig. 2). For further evaluation, we conducted ultrasonography of the shoulder. A minimally displaced extracapsular calcifications and defect of the cortical surface at the posterior area of the acromial process was noted (Fig. 3). We could diagnose avulsion fracture with ultrasonography. There was no deltoid or rotator cuff tear. Using real-time ultrasonography, lidocaine hydrochloride $0.5 \mathrm{~mL}$ and $40 \mathrm{mg}$ $(1 \mathrm{~mL})$ of triamcinolone acetonide was injected around the avulsion fracture of acromion. Anti-inflammatory medication was prescribed and the patient was advised not to do any activities that included lifting. After 4 days, the shoulder pain of patient was subjectively judged to be lessened by half. One month later, the shoulder pain was completely resolved and the patient achieved excellent shoulder function.

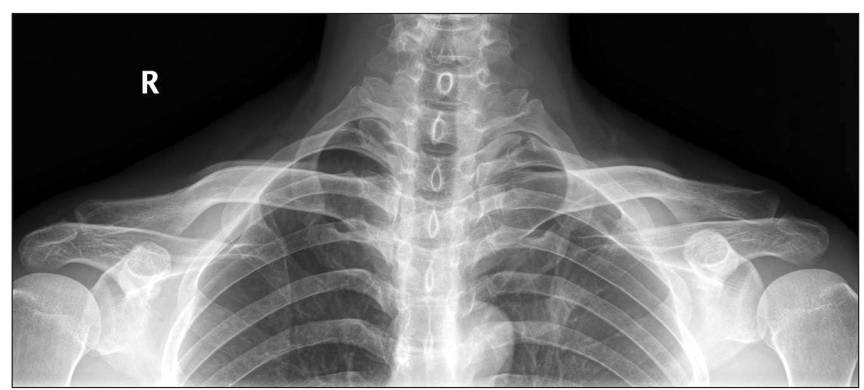

Fig. 1. The space between acromioclavicular joint is identical on both sides in the anterior-posterior view obtained with the both clavicles of the patient bearing weight. This finding suggests intact acromioclavicular ligament.

\section{DISCUSSION}

Avulsion fractures of acromion are thought to occur as a result of deltoid muscle forces, or as a result of strain from the acromioclavicular ligament $[7,8]$. In our case, the patient was found to have this type of fracture as a result of deltoid muscle forces.

In the diagnosis of non-displaced avulsion fractures, ultrasonography has advantages over simple radiographs. In a study that compared the diagnostic accuracy of simple radiography and ultrasonography for non-displaced shoulder fractures, initial detection rate for humeral fracture using simple radiology was only $45 \%$. With ultrasonography, the detection rate increased up to $59 \%$. Of 17 patients in whom initial radiologic examination was negative or equivocal, 10 were diagnosed as having fracture with ultrasonography [5].

Usually acromion can be observed well with simple radiographs, such as axillary lateral view and transthoracic lateral view. However, fractures of acromion rarely have displacement. Simple radiography has higher chances to miss the fracture. Although three-dimensional computed tomography could be useful as an additional examination, it is not appropriate as the screening test. It is relatively expensive and poses excessive radiation exposure. On the other hand, ultrasonography is a useful imaging

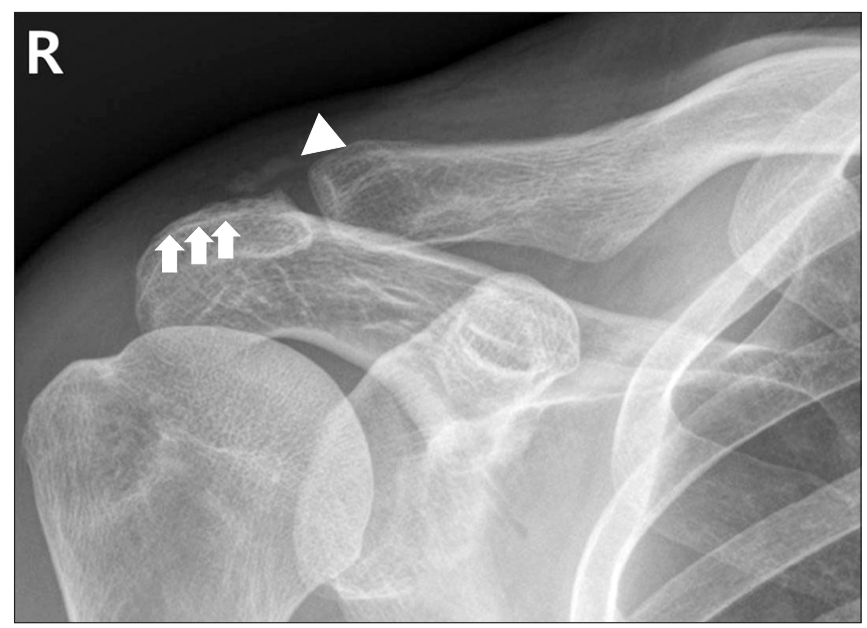

Fig. 2. Radiograph of shoulder in anterior-posterior view showed a small calcific deposit (arrowhead) and a possible fracture line (arrow) in the posterior area of the acromial process at right acromioclavicular joint. The possible fracture line was found after performing ultrasonography examination. 

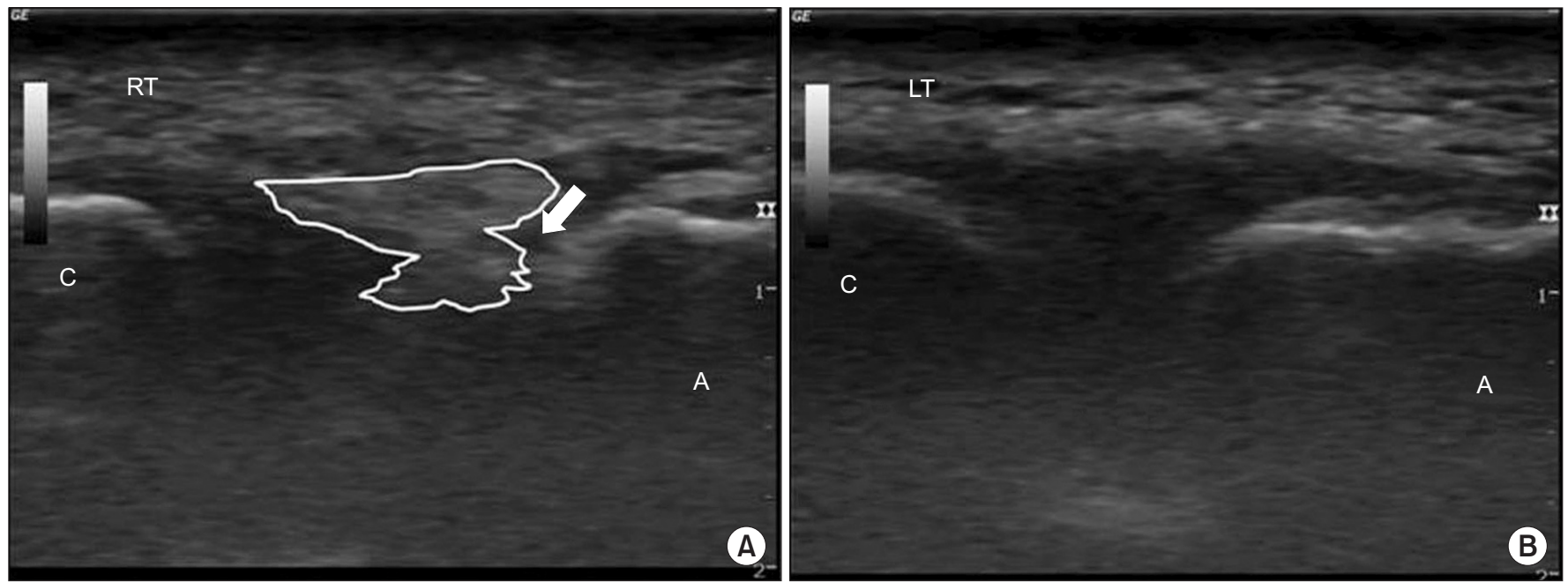

Fig. 3. Ultrasonographic image of acromioclavicular joint with oblique coronal view. (A) A minimally displaced extracapsular calcifications and defect (arrow) of the cortical surface at the acromion are shown. (B) Normal acromioclavicular joint on left side is shown. A, acromion; C, clavicle.

modality for the diagnosis. Although ultrasonic beam cannot pass through the cortical bone, bony irregularities and defects of the cortical surface of bone could be readily detected. Usefulness of ultrasonography for the diagnosis of fractures had been also verified in an experimental study. An experimental study found that fractures may appear as interruptions of the cortical echo or as dorsal bands of echoes limited to the fracture site depending on their size [9].

However, in the acute phase of the stress fractures, there are cases in which ultrasonography did not reveal cortical defects. In the acute phase of the stress fracture, only a thin hypoechoic line by local congestion, periosteal reaction and edema of soft tissue can be found. This may be difficult to detect using ultrasonography. Additionally ultrasonography cannot disclose internal bone structure.

This case study has several limitations. Bilateral ultrasonographic images of acromioclavicular joint with oblique coronal view were not exactly symmetrical mates. Ligament of acromioclavicular joint was obstructed by extracapsular calcifications. We wanted to compare ultrasonographic images of pretreatment with those of posttreatment. However the patient did not revisit. More definite ultrasonographic images are needed to overcome these limitations.

In conclusion, we report the first case report of nondisplaced avulsion fracture of the acromion that was confirmed with ultrasonography where simple radiography failed. Ultrasonography can be used in the early diagnosis of avulsion fracture. It can provide an early recovery through the proper treatment. Ultrasonography can be an excellent tool to identify a non-displaced fracture of acromion.

\section{CONFLICT OF INTEREST}

No potential conflict of interest relevant to this article was reported.

\section{REFERENCES}

1. Rockwood CA, Beaty JH, Kasser JR. Rockwood and Wilkins' fractures in children. 7th ed. Philadelphia: Lippincott Williams \& Wilkins; 2010.

2. Ada JR, Miller ME. Scapular fractures: analysis of 113 cases. Clin Orthop Relat Res 1991;(269):174-80.

3. Goss TP. The scapula: coracoid, acromial, and avulsion fractures. Am J Orthop (Belle Mead NJ) 1996;25: 106-15.

4. Kuhn JE, Blasier RB, Carpenter JE. Fractures of the acromion process: a proposed classification system. J Orthop Trauma 1994;8:6-13.

5. Patten RM, Mack LA, Wang KY, Lingel J. Nondisplaced fractures of the greater tuberosity of the humerus: sonographic detection. Radiology 1992;182:201-4.

6. Senall JA, Failla JM, Bouffard JA, van Holsbeeck M. Ul- 
trasound for the early diagnosis of clinically suspected scaphoid fracture. J Hand Surg Am 2004;29:400-5.

7. Heyse-Moore GH, Stoker DJ. Avulsion fractures of the scapula. Skeletal Radiol 1982;9:27-32.

8. Rask MR, Steinberg LH. Fracture of the acromion caused by muscle forces: a case report. J Bone Joint
Surg Am 1978;60:1146-7.

9. Grechenig W, Clement H, Schatz B, Klein A, Grechenig M. Die sonographische frakturdiagnostik: eine experimentelle studie. Biomed Technik 1997;42:13845. 